\title{
A Systematic Review and Meta-Analysis on the Relation Between Helicobacter Pylori Infection and Atherosclerosis in the Iranian Population
}

\author{
Masoud Keikha \\ Mashhad University of Medical Sciences \\ Mohsen Karbalaei ( $\Delta$ mohsen.karbalaei@jmu.ac.ir) \\ Jiroft University of Medical Sciences https://orcid.org/0000-0001-9899-2885
}

\section{Research}

Keywords: Helicobacter pylori, Atherosclerosis, Iran, Cardiovascular disease

Posted Date: May 6th, 2020

DOI: https://doi.org/10.21203/rs.3.rs-26342/v1

License: (c) (1) This work is licensed under a Creative Commons Attribution 4.0 International License.

Read Full License 


\section{Abstract}

Background: Various evidences have recently been provided indicating the relationship between infection with Helicobacter pylori and the extra-gastric complication, especially atherosclerosis. Atherosclerosis is the most important predisposing factor for cardiovascular disorders due to the high prevalence of cardiovascular disorders in developing countries (areas where a high population of people are infected with Helicobacter pylori), in particular in Iran.

Methods: In a current systematic review and meta-analysis study, we collected all studies of the isolation of Helicobacter pylori from atherosclerotic plaques in Iranian cardiovascular patients to investigate the presence or absence of a relationship between Helicobacter pylori infection and susceptibility to atherosclerosis. The present meta-analysis was done by Comprehensive Meta-Analysis software (CMAVer. 2.0). This software has the ability to combine studies and impact sizes into the results and is highly acceptable.

Results: Overall, the frequency of $H$. pylori in atherosclerotic plaques in the coronary artery disease (CAD) patients was estimated to be $41.30 \%$. However, the highest and lowest frequency of infection with Helicobacter pylori were $80 \%$ and $0 \%$, respectively.

Conclusions: However generally, regarding the previous studies, we collected all the Iranian published articles and showed that the infection with Helicobacter pylori was significantly related with the atherosclerosis, but further complementary and more extensive studies are required to confirm this hypothesis.

\section{Background}

Cardiovascular disease (CVD) is the most common cause of mortality worldwide ( $50 \%$ of global mortality), with an unprecedented increase in the rate of coronary artery disease (CAD) mortality in the last two decades and it has become one of the most significant concerns of the global health system [13]. Atherosclerosis is undoubtedly the most important predisposing factor for cardiovascular disorders with a high prevalence in the developed as well as the developing countries [2-5]. Atherosclerosis is a chronic procedure with several factors being involved in its formation [6]. Based on the available evidence, traditional risk factors such as smoking, obesity, hypertension, hypercholesterolemia, and host genome polymorphisms have not had important impacts on the pathogenesis of atherosclerosis, and recent studies suggest that inflammatory diseases play a central role in this respect [7-8]. Infectious agents are considered as the most important inflammatory triggers in the body as well as a risk factor for atherosclerosis due to the stimulating the inflammatory procedure and damaging vascular endothelial cells [9-10]. According to the review of the literature, the most important infectious agents that are associated with atherosclerosis include: Chlamydia pneumoniae, Hepatitis $C$ virus, Human Immunodeficiency virus, Epstein-Barr virus, Hepatitis B virus, Human T lymphotropic virus type I, Cytomegalovirus, Mycobacterium tuberculosis and Helicobacter pylori [11-17]. Helicobacter pylori (H. 
pylori) is a gram-negative, of microaerophilic and spiral form that resides in the human gastric mucosa layer and is an etiologic agent of chronic gastritis, gastric ulcer, duodenal ulcer, and gastric cancer [18]. Recent studies have shown that $H$. pylori is also isolated from dental plaques, human saliva, duodenum, feces and atherosclerotic plaques and is strongly related with the extra-gastrointestinal disorders such as idiopathic thrombocytopenic purpurae, neurological disorders (stroke events), psychiatric, gynecological, pre- Eclampsia, infertility, glaucoma, dermatologic complications, lung cancer, iron deficiency anemia, and atherosclerosis [19-30]. Unfortunately, the rate of colonization with $H$. pylori is high worldwide, especially in Asia (from $25-50 \%$ in the developed countries to $90 \%$ in the developing countries), and despite the eradication of $\mathrm{H}$. pylori infection due to the destruction of antibiotics in acidic stomach conditions, the influence of the bacterium under the gastric mucus and the antibiotic resistance has been reduced in the recent years [31-33]. According to the review of the literature, the rate of gastric cancer in Asia is higher than in the western countries, and many researchers attribute this to the high rate of colonization with $H$. pylori in this geographical region [34-35]. Moreover, the rate of atherosclerosis in the developing countries (where the rate of colonization with Helicobacter pylori is $90 \%$ ) is higher than in the developed countries [4, 36-37]. The hypothesis of the correlation between $H$. pylori and atherosclerosis was first suggested by Mendall et al. in 1994 [38]. Despite extensive studies about the correlation of infection with H. pylori and atherosclerosis, it seems that one of the most important reasons for increasing the rate of atherosclerosis in the developing countries may be the high prevalence of colonization with $\mathrm{H}$. pylori in these regions, especially since $H$. pylori has been isolated from atherosclerotic plaques of the patients [39-41]. However, some resources have rejected the relationship between $\mathrm{H}$. pylori and atherosclerosis, and there is no precise response to the question. Thus, more extensive studies are required in this respect. [42-44]. The rate of atherosclerosis and cardiovascular disorders in Iran is high and based on the Iranian Society of Atherosclerosis, 300 deaths occur each day due to cardiovascular diseases in Iran. Moreover, considering that the high rate of colonization with H. pylori in Iran (estimated to be more than $85 \%$ ), Iran is regarded as one of the most appropriate places to investigate the possible association between $H$. pylori infection and atherosclerosis, and the present study was conducted to investigate the relationship between the colonization with $H$. pylori and susceptibility to atherosclerosis in the Iranian patients.

\section{Methods}

\subsection{Search strategy}

The present comprehensive meta-analysis was fulfilled based on the PRISMA guideline proposed by Liberati et al. [45]. $t$ was intended in this study to evaluate the relation between colonization with Helicobacter pylori in cardiovascular patients with atherosclerotic plaques. For this purpose, the related articles the systematic literature searches in PubMed, Scopus, Google scholar databases and the domestic databases such as Iranmedex, SID, ISC and Magiran were collected considering the combination keywords including Helicobacter pylori, Iran, atherosclerosis, atherosclerotic plaques, cardiovascular diseases, DNA, Infection, Coronary artery disease and coronary arteries; in addition original articles and congress abstracts were studied independently by two the authors, without 
considering the range of the required time. Finally, the duplicate articles were eliminated and the abstract and title of the studies were selected based on the eligible criteria (Fig. 1).

\subsection{Selection criteria}

The screening process of the studies was performed independently by two the authors. The titles and abstracts were initially evaluated; inclusion criteria included 1 ) studies on the isolation of $H$. pylori from atherosclerosis plaques, 2) the patients with cardiovascular disorders, 3) the studies limited to Iran, 4) cross-sectional, cohort and case-control studies, 5) method of Helicobacter infection diagnosis consisting of culture, PCR and serology (detection of $\operatorname{lgG}$ ), and 6) studies in English and Farsi languages. However, the exclusion criteria were: 1) in vitro studies and lab animals, 2) studies containing inadequate or inadequate method or results, 3) case reports and review articles, 4) simultaneous co-infection with Helicobacter pylori and other infectious agents, 5) duplicate articles, and 6) not-free articles. It is to note that a study included in our study, despite being a letter to the editor, since it was subject to the eligible criteria.

\subsection{Quality assessment and data extraction}

The Joanna Briggs Institute (JBI) critical appraisal checklist (Data not shown) was used to evaluate the quality of the studies based on eligibility of criteria. Information such as the author, publishing year, province, diagnostic methods and frequency of $H$. pylori isolates were listed in Table 1 among CAD patients with atherosclerosis plaques. 
Table 1

Characteristics of the Iranian studies about frequency of $\mathrm{H}$. pylori in the CAD patients

\begin{tabular}{|c|c|c|c|c|c|c|c|}
\hline \multirow[t]{2}{*}{ Authors } & \multirow[t]{2}{*}{ Year } & \multirow[t]{2}{*}{ Provinces } & \multicolumn{3}{|c|}{ Atherosclerosis plaque } & \multirow{2}{*}{$\begin{array}{l}\text { Diagnostic } \\
\text { method }\end{array}$} & \multirow[t]{2}{*}{$\operatorname{Re}$} \\
\hline & & & $\begin{array}{l}\text { No. HP } \\
\text { positive }\end{array}$ & Total & $N(\%)$ & & \\
\hline Abibiglou et al. & 2018 & $\begin{array}{l}\text { East } \\
\text { Azerbaijan }\end{array}$ & 1 & 28 & 3.57 & PCR & 47 \\
\hline Izadi et al. & 2012 & Tehran & 56 & 105 & 53.33 & PCR/serology & 48 \\
\hline $\begin{array}{l}\text { Gharehdaghi et } \\
\text { al. }\end{array}$ & 2018 & Tehran & 10 & 90 & 11.11 & PCR & 49 \\
\hline Sadeghian et al. & 2019 & $\begin{array}{l}\text { Khorasan } \\
\text { Razavi }\end{array}$ & 0 & 30 & 0 & PCR & 20 \\
\hline Nozari et al. & 2009 & Tehran & 56 & 70 & 80 & Serology & 50 \\
\hline Yazdi et al. & 2014 & Tehran & 1 & 90 & 1.11 & Culture & 51 \\
\hline Pouria et al. & 2009 & Kermanshah & 8 & 30 & 26.66 & Serology & 52 \\
\hline $\begin{array}{l}\text { Vafaeimanesh } \\
\text { et al. }\end{array}$ & 2014 & Qom & 47 & 62 & 75.80 & Serology & 53 \\
\hline Sayyah et al. & 2012 & Qazvin & 32 & 40 & 68.08 & Serology & 54 \\
\hline Ansari et al. & 2010 & Urmia & 49 & 100 & 49 & Serology & 55 \\
\hline Davoudi et al. & 2010 & Tehran & 40 & 69 & 57.97 & Serology & 56 \\
\hline Ashtari et al. & 2006 & NR & 29 & 42 & 69.04 & Serology & 57 \\
\hline
\end{tabular}

\subsection{Data analysis}

The possible relationship between Helicobacter pylori infection and atherosclerosis in atherosclerotic plaque samples of the Iranian CAD patients was evaluated and reported using the odds ratio (OR) at 95\% confidence intervals $(95 \% \mathrm{Cis}$ ) (random effects models when the heterogeneity was high; heterogeneity was assessed using $l^{2}$ statistic and Cochrane $Q$ statistic; $P>25 \%$ and $P$-value $\left.<0.1\right)$. The statistical analysis for this study was done by Comprehensive Meta-Analysis (CMA) software-Ver. 2.0 (Biostat, Englewood, $\mathrm{NJ}$ ) [46], and the publication bias were also measured by the asymmetry of the funnel plot.

\section{Results}

A total of 94 articles were considered from the databases of PubMed, Scopus, Google scholar, and Iranian databases. After omitting the duplicate studies, the rest of the articles were entered in Endnote software, and the title, abstract and full-text of the articles were reviewed and collected on the basis of 
eligible criteria for the cross-sectional, case-control and cohort studies regarding the isolation of Helicobacter pylori from the atherosclerotic plaques in the Iranian CAD patients. Ultimately, 12 studies consisting of the original articles and congress abstracts included in the comprehensive meta-analysis (Fig. 1).

Population distribution, characteristics of studies and diagnostic methods of the studies were summarized in Table 1. Since the forms of the cardiovascular disease were not mentioned in a significant number of the studies, the patients were not categorized in the subgroups and the frequency of Helicobacter pylori infection was calculated simultaneously for all the CAD patients. Overall, the frequency of $H$. pylori in atherosclerotic plaques in the CAD patients was estimated to be $41.30 \%$. However, the highest and lowest frequency of infection with Helicobacter pylori were $80 \%$ and $0 \%$, respectively. In addition, the odds ratio was used to evaluate the relationship between infection with Helicobacter pylori and atherosclerosis. Based on the available evidence, the odds ratio appeared to be more reliable, in terms of the considered outcomes, than the relative risk method in the low populations and in the unavailability of incidences within the community to investigate the significant relations and therefore we used the odds ratio method for our purpose [58]. The present meta-analysis was done by Comprehensive Meta-Analysis software (CMA-Ver. 2.0). This software has the ability to combine studies and impact sizes into the results and is highly acceptable and commonly used [59]. Statistical analysis revealed that infection with Helicobacter pylori was significantly related with the atherosclerosis (The ORs $95 \%$ Cl: $2.50(1.83,3.42)$; P-value $<0.00)$ and the infection with $H$. pylori is predisposed to atherosclerosis and cardiovascular disorders in Iran (Fig. 2). Also, the asymmetry of the funnel plot demonstrated the potential publication bias in the present study (Fig. 3). However, the present study was also a comprehensive document confirming the relationship between the infection with Helicobacter pylori in atherosclerotic plaques formation and the susceptibility to CAD.

\section{Discussion}

Atherosclerosis is the most common cause of cardiovascular diseases, especially the ischemic heart disease and stroke, and is among the top four causes of death worldwide [60]. Atherosclerosis is a compound Greek word for athero meaning gruel or paste and sclerosis meaning hardness; it is a disorder of large and medium arteries that begins with damage to the vascular endothelial cells and changes in the blood circulation and subsequent to the formation of the atherosclerosis plaques including the necrotic cores, calcified region, lipid particles, smooth muscle cells (SMCs), endothelial cells (ECs), polymorphonuclear cells (PMNs) and foamy cells (alternative macrophages) [60-61]. According to the available evidence, the most prominent stimulants for the formation and development of the atherosclerotic plaques are processes of vascular endothelium damage (especially the intima) and the chronic inflammation [60-62]. Infectious agents, especially Chlamydia pneumoniae, Mycobacterium tuberculosis and Helicobacter pylori, are among the most important infections that can cause chronic inflammation to escape the immune system and appear to be involved in the formation of the atherosclerotic plaques [20]. The hypothesis of the role of Helicobacter pylori infection and atherosclerosis was first reported by Menall et al. and the track of Helicobacter pylori infection has been 
observed in atherosclerotic plaques of coronary, carotid and aortic arteries [38, 63]. In particular, the eradication of $H$. pylori infection decreased the CRP and proinflammatory response and improved the endothelial dysfunction and protective effect on early stages of the atherosclerosis formation [64-66]. In the present study, we collected and analyzed all the published articles about Helicobacter pylori infection in the Iranian cardiovascular patients, since the prevalence of atherosclerosis is high in Iran and a significant population in Iran is infected with $\mathrm{H}$. pylori. Thus, the studies about the Iranian patients can provide very valuable results regarding the impact of $H$. pylori infection and the susceptibility to cardiovascular disorders. According to the present comprehensive meta-analysis, the rate of colonization with Helicobacter pylori and the formation of atherosclerotic plaques in the Iranian CAD patients are significantly related and may make the individuals susceptible to the cardiovascular disorders. According to the literature review, Helicobacter pylori contributes to the formation of the atherosclerotic plaques and CAD through the chronic inflammation, injuries and endothelial dysfunction, as well as the impaired body metabolism (Fig. 4). Studies have shown that chronic inflammation during atherosclerosis stimulates Th1 activity and causes the production of pro-inflammatory responses that result in calling and recruiting the inflammatory cells especially PMNs subsequent to the IL-1, IL-6, IFN-Y and TNF-a production, and macrophages also enter into the location in response to MCP1 / 2, inducing the inflammatory reactions that result in the destruction and dysfunction of the endothelial cells $[61-63,67-68]$. Since H. pylori is capable of inducing the chronic inflammatory and Th1 response, it seems that it may be involved in the pathogenesis of atherosclerosis [67-68]. Furthermore, $H$. pylori can in some cases of chronic gastritis lead to atrophy and malabsorption of vitamin B12 and folic acid by stopping the gastric acid production, resulting in high levels of homocysteine, which increases the damage to the vessel wall through the stimulation of nitric oxide (NO) production and inflammation, and its serum level is elevated in a large number of patients affected by atherosclerosis and CAD [69-72]. According to existing studies, the people infected with $H$. pylori develop dyslipidemia [73]. Hoffmeister et al. demonstrated that the CAD patients infected with Helicobacter pylori had higher levels of cholesterol, LDL, triglyceride, and apolipoprotein-B as compared to the CAD patients infected with chlamydia pneumonia or cytomegalovirus, and the HDL levels of these patients were also lower [74]. However, similar studies have shown that after eradication of the infection with $H$. pylori, the serum levels of HDL and apolipoprotein-Al / All increase and cholesterol, triglyceride, while that of the LDL levels decrease. It seems that helicobacter pylori increase the fatty acid by disrupting the fatty acid metabolism and causes it to be deposited on the vessel wall [73-75]. Metabolic disorders can also provide the of incidence of atherosclerosis [76]. Gillum et al. showed that there was a significant relationship between $H$. pylori seropositivity and CAD in the diabetic patients [77]. Moreover, de Luis showed that the rate of CAD and cerebrovascular disorders between the diabetic patients infected with $H$. pylori is high [78]. In his studies, Polyzos et al. proved that infection with $H$. pylori is associated with resistance to insulin, and perhaps the infection with $H$. pylori via the impact on the metabolism (particularly glucose) of the body might lead to atherosclerosis, especially since the glucose resistance is improved subsequent to the eradication of infection with $H$. pylori and the level of the adiponectin (a factor for preventing metabolic disorders) is increased [79-80]. Processes such as hypertension and arterial stiffness have been implicated in the process of atherosclerosis, and studies have shown that there is a significant relationship between infection with helicobacter pylori and 
these factors [81-82]. Recently, the effect of Helicobacter pylori virulence factors has also been studied on atherosclerosis, and a previous report has shown a significant relationship between the infection with cytotoxin-associated gene A (CagA) positive strains and carotid plaque [83]. Also, Bastiani et al. showed that $H$. pylori CagA seropositivity was very high in the patients who encountered stroke [84]. It has been found in this respect that CagA strains induce atherosclerosis by the destruction of the vascular endothelial cells, modification of the oxidized LDL and stimulating the inflammation, and eradicating $H$. pylori CagA infection has stopped the above processes having a protective effect in the patients [85-87]. In addition, it has nowadays been suggested that CagA and HSPs stimulate the production of autoantibodies and endothelial dysfunction that ultimately lead to atherosclerosis [88-89]. There have been numerous reports about the relationship between Helicobacter pylori infection and the cardiovascular disease (CAD) $[63,89]$. According to the literature review, Longo-Mbenza et al. evaluated the cardiovascular risk factors, in a longitudinal (provident) study, in 205 patients for a ten-year follow-up and showed that $H$. pylori lgG titers were high in a substantial population of CAD patients [90]. In their studies on a population of 2029 in South Korea, Park et al. demonstrated that there was a significant relationship between $H$. pylori seropositivity and the CAD patients (ORs: 1.23; $p=0.049$ ) [91]. Other casecontrol studies conducted in India, Turkey, and Japan confirmed the results of previous studies [91-94]. Our study also confirmed the relationship between Helicobacter pylori infection and atherosclerosis in the CAD patients. Isolation of $H$. pylori from the atherosclerotic plaques is one of the most important evidence for approval of the role of this microorganism in the atherosclerosis and CAD $[63,89]$. Extensive studies are so far fulfilled in this regard. For instance, the rate of isolation of $\mathrm{H}$. pylori from atherosclerosis was $27.2-33.5 \%$ in the study by Jha et al. [92]. In another study in Argentina, the carotid plaque isolation was about 83\% [95]. In a cross-sectional study in Turkey, Kilic et al. found that the rates of $H$. pylori isolation from the atherosclerotic plaques and non-atherosclerotic vascular wall specimens were $48.2 \%$ and $19.2 \%$, respectively [96]. However, $\mathrm{H}$. pylori was not isolated from any atherosclerotic plaques in the studies in Italy and Poland [97-98]. Rahmani et al. demonstrated in their meta-analysis study that there was a significant relationship between the infection with $H$. pylori and Myocardial infraction in the Iranian patients (ORs = 2.53) [99]. In a meta-analysis of 18 epidemiological studies Danesh et al. found no significant relationship between $\mathrm{H}$. pylori infection and the coronary heart disease (CHD) [100]. In a meta-analysis that Zhong et al. did on a 4041 population of stroke patients, it was shown that there was a significant relationship between $\mathrm{H}$. pylori infection and ischemic stroke [21]. In another study by Zhong et al., it was found that there was a significant relationship between $H$. pylori infection and the coronary artery disease in the European (ORs: 2.11) and US (ORs: 1.43) patient populations [101]. However, in another meta-analysis, 13 studies were reviewed and no significant relationship was found between $H$. pylori and the stroke [102]. Recent studies have suggested that infection with strains lacking CagA and vacuolating cytotoxin A (VacA) may lead to controversial results. Thus, the role of virulence helicobacter pylori factors and the cardiovascular disorders have been considered in the recent studies $[63,89]$. In a study on 684 CAD patients, Mayr et al. showed that infection with CagA strains has a significant relationship with the atherosclerosis $(P=0.08)$ [103]. In a crosssectional study on seven case-control studies, Cremonini et al. found a significant relationship between the stroke and CagA seropositivity (ORs: 1.65) [104]. In their studies, Sun et al. showed that there was no 
relationship between $H$. pylori CagA + strains infection and the coronary heart disease (CHD) (ORs: 0.8) [105].

\section{Conclusions}

We had limitations in this study, the first of which was the limited number of studies that required more extensive studies. Moreover, in some studies, the diagnosis of $H$. pylori was based on the evaluation of $H$. pylori IgG seropositivity, but this test also yielded false positive results after the treatments. Thirdly, studies were restricted to geographic regions and this led to the selection bias. Fourthly, the type of CAD was not considered in several studies (e.g. coronary disease, ischemia, stroke, etc.). Fifthly, the studies were of case-control and cross-sectional basis, while the provident (longitudinal) studies were more appropriate for investigations of this study. Sixth, the virulence factors such as CagA and VacA were not suggested, and the seventh point was about the publication bias of the studies. However generally, regarding the previous studies, we collected all the Iranian published articles and showed that the infection with Helicobacter pylori was significantly related with the atherosclerosis, but further complementary and more extensive studies are required to confirm this hypothesis.

\section{List Of Abbreviations}

Helicobacter pylori (H. pylori)

Cardiovascular disease (CVD)

Coronary artery disease (CAD)

Coronary heart disease (CHD)

Nitric oxide (NO)

Cytotoxin-associated gene A (CagA)

Vacuolating cytotoxin A (VacA)

Joanna Briggs Institute (JBI)

Smooth muscle cells (SMCs)

Endothelial cells (ECs)

Polymorphonuclear cells (PMNs)

\section{Declarations}

- Ethics approval and consent to participate 
The manuscript methods was based on researching on global databases.

- Consent for publication

All authors have consent for publication of data

- Availability of data and materials

All data generated or analyzed during this study are included in this published article

- Competing interests

The authors declare that they have no competing interests

- Funding

The funding has no received for this manuscript

- Authors' contributions

All authors are medical bacteriologist

- Acknowledgements

We appreciate from both Jirof University of Medical Sciences and Mashhad University of Medical Sciences.

\section{References}

1. Frederick Js, Kumar V, Abbas AK, Fausto N. Blood vessels. In: Robbins and Cotran pathologic basis of disease. Pennsylvania: Elsevier Saunders; 2010. p. $496 \mathrm{e} 506$.

2. Shah AS, Stelzle D, Lee KK, Beck EJ, Alam S, Clifford S, Longenecker CT, Strachan F, Bagchi S, Whiteley W, Rajagopalan S, et al. Global burden of atherosclerotic cardiovascular disease in people living with HIV: systematic review and meta-analysis. Circulation. 2018;138(11):1100-12.

3. Lee KK, Stelzle D, Bing R, Anwar M, Strachan F, Bashir S, Newby DE, Shah JS, Chung MH, Bloomfield GS, Longenecker CT, et al. Global burden of atherosclerotic cardiovascular disease in people with hepatitis $\mathrm{C}$ virus infection: a systematic review, meta-analysis, and modelling study. The Lancet Gastroenterology Hepatology. 2019;4(10):794-804.

4. Ueshima H, Sekikawa A, Miura K, Turin TC, Takashima N, Kita Y, Watanabe M, Kadota A, Okuda N, Kadowaki T, Nakamura, Ym, et al. Cardiovascular disease and risk factors in Asia: a selected review. Circulation. 2008;118(25):2702-9.

5. Moradi M, Varasteh E. Coronary atherosclerosis evaluation among Iranian patients with zero coronary calcium score in computed tomography coronary angiography. Advanced biomedical 
research. 2016;5.

6. Jacotot B. Atherosclerosis, a multifactor lesion justifying multirisk care. Atherosclerosis. 1994;110:1-2.

7. Nouzari Y, Akiash N, Ebrahimi DN. Association between Helicobacter pylori infection and atherosclerotic coronary artery disease. Iranian Journal of Pathology. 2009;4(1):1-4.

8. Fong IW. Emerging relations between infectious diseases and coronary artery disease and atherosclerosis. Cmaj. 2000;163(1):49-56.

9. Hansson GK, Libby P. The immune response in atherosclerosis: a double-edged sword. Nature reviews immunology. 2006;6(7):508-19.

10. Jonsson AL, Bäckhed F. Role of gut microbiota in atherosclerosis. Nature Reviews Cardiology. 2017;14(2):79.

11. Jha HC, Srivastava P, Divya A, Prasad J, Mittal A. Prevalence of Chlamydophila pneumoniae is higher in aorta and coronary artery than in carotid artery of coronary artery disease patients. APMIS. 2009;117:905e11.

12. Tien PC, Schneider MF, Cole SR, Cohen MH, Glesby MJ, Lazar J, et al. Association of hepatitis C virus and HIV infection with subclinical atherosclerosis in the women's interagency HIV study. AIDS. 2009;24:1781e4.

13. Ghotaslou R, Aslanabadi N, Ghojazadeh M. Hepatitis B virus infection and the risk of coronary atherosclerosis. Ann Acad Med Singap. 2008;37:913e5.

14. Muller BT, Huber R, Henrich B, Adams O, Berns G, Siebler M, et al. Chlamydia pneumoniae, herpes simplex virus and cytomegalovirus in symptomatic and asymptomatic high-grade internal carotid artery stenosis. Does infection influence plaque stability? Vasa. 2005;34:163e9.

15. Apostolou F, Gazi IF, Lagos K, Tellis CC, Tselepis AD, Liberopoulos EN, et al. Acute infection with Epstein-Barr virus is associated with atherogenic lipid changes. Atherosclerosis. 2010;212:607e13.

16. Rota S. Mycobacterium tuberculosis complex in atherosclerosis. Acta Med Okayama. 2005;59:247e51.

17. Ayada K, Yokota K, Hirai K, Fujimoto K, Kobayashi K, Ogawa H, Hatanaka K, Hirohata S, Yoshino T, Shoenfeld Y, Matsuura E. Regulation of cellular immunity prevents Helicobacter pylori-induced atherosclerosis. Lupus. 2009;18(13):1154-68.

18. McColl KE. Helicobacter pylori infection. N Engl J Med. 2010;362(17):1597-604.

19. Kim N, Lim SH, Lee KH, You JY, Kim JM, Lee NR, Jung HC, Song IS, Kim CY, et al. Helicobacter pylori in dental plaque and saliva. Korean J Intern Med. 2000;15(3):187.

20. Sadeghian MH, Yazdi SA, Ayatollahi H, Ghazvini K, Keramati MR, Karimiani EG, Sheikhi M, Ahrarirodi SV, Shaghayegh G, et al. Absence of Helicobacter pylori infection in coronary atherosclerosis disease in Northeast of Iran. Artery Research. 2013;7(3-4):211-5.

21. Wang ZW, Li Y, Huang LY. Helicobacter pylori infection contributes to high risk of ischemic stroke: evidence from a meta-analysis. J Neurol. 2012;259(12):2527-37. 
22. Roubaud Baudron C, Letenneur L, Langlais A. Personnes Agées QUID Study. Does Helicobacter pylori infection increase incidence of dementia? The Personnes Agées QUID Study. J Am Geriatr Soc. 2013;61(1):74-8.

23. Shaban MM, Kandil HO, Elshafei AH. Helicobacter Pylori Seropositivity in Patients with Hyperemesis Gravidarum. Am J Med Sci. 2014;347(2):101-5.

24. Franceschi F, Di Simone N, D'Ippolito S. Antibodies anti-CagA cross-react with trophoblast cells: a risk factor for pre-eclampsia? Helicobacter. 2012;17(6):426-34.

25. Ambrosini G, Andrisani A, Fiore C. AntiHelicobacter pylori antibodies in cervical mucus: a new cause of infertility. Eur J Obstet Gynecol Reprod Biol. 2011;155(2):157-60.

26. Bagnis A, Izzotti A, Saccà SC. Helicobacter pylori, oxidative stress and glaucoma. Dig Liver Dis. 2012;44(11):963-4.

27. Magen E, Mishal J. Possible benefit from treatment of Helicobacter pylori in antihistamine-resistant chronic urticaria. Clin Exp Dermatol. 2013;38(1):7-12.

28. Deng B, Li Y, Zhang Y. Helicobacter Pylori Infection and Lung Cancer: A Review of an Emerging Hypothesis. Carcinogenesis. 2013;34(6):1189-95.

29. Papagiannakis P, Michalopoulos $C$, Papalexi F. The role of Helicobacter pylori infection in hematological disorders. Eur J Intern Med. 2013;24(8):685-90.

30. Payandeh M, Sohrabi N, Zare ME. Platelet Count Response to Helicobacter pylori Eradication in Iranian Patients with Idiopathic Thrombocytopenic Purpura. Mediterr J Hematol Infect Dis. 2012;4(1):e2012056.

31. Dunn BE, Cohen H. Blaser MJ. Helicobacter pylori. Clin Microbiol Rev. 1997;10:720-41.

32. Suerbaum S. Michetti p. Helicobacter pylori infection. n Engl J Med. 2002;347(15):1175-86.

33. Bazzoli F, Pozzato P, Rokkas T. Helicobacter pylori: the challenge in therapy. Helicobacter. 2002;7:439.

34. Singh K, Ghoshal UC. Causal role of Helicobacter pylori infection in gastric cancer: an Asian enigma. World Journal of Gastroenterology: WJG. 2006;12(9):1346.

35. Yamaoka Y, Kato M, Asaka M. Geographic differences in gastric cancer incidence can be explained by differences between Helicobacter pylori strains. Internal medicine. 2008;47(12):1077-83.

36. Wong MC, Wang HH. Rapid emergence of atherosclerosis in Asia: a systematic review of coronary atherosclerotic heart disease epidemiology and implications for prevention and control strategies. Curr Opin Lipidol. 2015;26(4):257-69.

37. Ansari R, Khosravi A, Bahonar A, Shirani S, Kelishadi R, Khosravi Z, et al. Risk factors of atherosclerosis in male smokers, passive smokers, and hypertensive nonsmokers in central Iran. ARYA atherosclerosis. 2012;8(2):90.

38. Mendall MA, Goggin PM, Molineaux N, Levy J, Toosy T, Strachan D, Camm AJ, Northfield TC, et al. Relation of Helicobacter pylori infection and coronary heart disease. Heart. 1994;71(5):437-9. 
39. Chmiela M, Gajewski A, Rudnicka K. Helicobacter pylori vs coronary heart disease-searching for connections. World J Cardiol. 2015;7(4):187.

40. He C, Yang Z, Lu NH. Helicobacter pylori an infectious risk factor for atherosclerosis?. Journal of atherosclerosis and thrombosis. 2014:25775.

41. Ameriso SF, Fridman EA, Leiguarda RC, Sevlever GE. Detection of Helicobacter pylori in Human Carotid Atherosclerotic Plaque. STROKE-DALLAS-. 2001;32(2):385-9.

42. Jia EZ, Zhao FJ, Hao B, Zhu TB, Wang LS, Chen B, Cao KJ, Huang J, Ma WZ, Yang ZJ, Zhang G, et al. Helicobacter pylori infection is associated with decreased serum levels of high density lipoprotein, but not with the severity of coronary atherosclerosis. Lipids in Health Disease. 2009;8(1):59.

43. Zhu J, Quyyumi AA, Muhlestein JB, Nieto FJ, Horne BD, Zalles-Ganley A, Anderson JL, Epstein SE, et al. Lack of association of Helicobacter pylori infection with coronary artery disease and frequency of acute myocardial infarction or death. The American journal of cardiology. 2002;89(2):155-8.

44. Lee SY, Kim DK, Son HJ, Lee JH, Kim YH, Kim JJ, Paik SW, Rhee JC, et al. The impact of Helicobacter pylori infection on coronary heart disease in a Korean population. The Korean journal of gastroenterology. 2004;44(4):193-8.

45. Liberati A, Altman DG, Tetzlaff J, Mulrow C, Gøtzsche PC, loannidis JP, Clarke M, Devereaux PJ, Kleijnen J, Moher D, et al. The PRISMA statement for reporting systematic reviews and metaanalyses of studies that evaluate health care interventions: explanation and elaboration. Ann Intern Med. 2009;151(4):W-65.

46. von Hippel PT. The heterogeneity statistic I 2 can be biased in small meta-analyses. BMC Med Res Methodol. 2015;15(1):35.

47. Abibiglou SS, Baghi HB, Memar MY, Safaei N, Parvizi R, Banani M, Alizadeh N, Ghotaslou R, et al. The Presence of Porphyromonas Gingivalis, Chlamydia Pneumonia, Helicobacter Pylori, Mycoplasma Pneumonia and Enterobacter Hormaechei DNA in the Atherosclerotic Plaques. Journal of Research in Medical Dental Science. 2018;6(3):1-6.

48. Izadi M, Fazel M, Sharubandi SH, Saadat SH, Farahani MM, Nasseri MH, Dabiri H, SafiAryan R, Esfahani AA, Ahmadi A, Jafari NJ, et al. Helicobacter species in the atherosclerotic plaques of patients with coronary artery disease. Cardiovascular Pathology. 2012;21(4):307-11.

49. Gharehdaghi J, Nasr R, Khezerloo JK, Eidgahi MR, Tabasi M, Ghasemi M, Mozaffari E, Azizian R, Eskandarion MR, et al. Detection of H. pylori Infection in Atherosclerotic Plaques of 180 Corpses in Referred to Forensic Medicine Center of Tehran in. Iran J Public Health. 2018;47(11):1780-2.

50. Nouzari Y, Akiash N, EBRAHIMI DN. Association between Helicobacter pylori infection and atherosclerotic coronary artery disease. Iranian Journal of Pathology. 2009;4;(1):1-4.

51. Yazdi MM, Moradi SL, Rad PK, Benvidi ME, Eslami G, Taherpour A, Taheri S, et al. Investigating the Presence of Helicobacter Pylori in Atheroma Plaques of Arteries in Patients with Atherosclerosis. Iranian Journal of Public Health. 2014;43(2):189.

52. Pooria A, Maasoomi M, Rafiee E, Sabzi F, Rezaee M, Hossain Zadegan H, et al. Relationship between Chlamydia pneumonia and Helicobacter pylori with atherosclerosis. YAFTE. 2009;10(2):3-11. 
53. Vafaeimanesh J, Hejazi SF, Damanpak V, Vahedian M, Sattari M, Seyyedmajidi M, et al. Association of Helicobacter pylori infection with coronary artery disease: is Helicobacter pylori a risk factor?. The Scientific World Journal. 2014;2014.

54. Sayyah S, Akbarian M, Abdollah-Salimi S, Tavakoli M, Pahlevan AA. Coexistence of gastric Helicobacter pylori infection and coronary artery diseases in Qazvin (Iran). JQUMS. 2012;16:36-43.

55. Khadem Ansari MH, Rasmi Y, Manafi M, Rahimipour A, Ghadermarzi E. The evaluation of Helicobacter pylori infection and cardiovascular disease risk factors with atherosclerosis. Stud Med Sci. 2010;21(1):17-23.

56. Davoudi S, Omran AS, Boroumand MA, Rahimian N, Saadat S. Association between Helicobacter. pylori and coronary artery disease. Cent Eur J Med. 2011;6(1):107-12.

57. Ashtari F, Shaigannezhad V, Saberi A, Rabiei E. Relationship between Helicobacter pylori immunoglobulin $G$ antibody and thrombotic ischemic stroke. Acta Medica Iranica. 2008;46(4):3036.

58. Schmidt CO, Kohlmann T. When to use the odds ratio or the relative risk? International journal of public health. 2008;53(3):165.

59. Richy F, Bruyere O, Ethgen O, Cucherat M, Henrotin Y, Reginster JY, et al. Structural and symptomatic efficacy of glucosamine and chondroitin in knee osteoarthritis: a comprehensive meta-analysis. Arch Intern Med. 2003;163(13):1514-22.

60. Gisterå A, Hansson GK. The immunology of atherosclerosis. Nat Rev Nephrol. 2017;13(6):368.

61. Galkina E, Ley K. Immune and inflammatory mechanisms of atherosclerosis. Annu Rev Immunol. 2009;27:165-97.

62. Libby P, Buring JE, Badimon L, Hansson GK, Deanfield J, Bittencourt MS, Tokgözoğlu, Lewis EF, et al. Atherosclerosis Nat Rev Dis Primers. 2019;5(1):56.

63. Karbasi-Afshar R, Khedmat $\mathrm{H}$, Izadi M. Helicobacter pylori Infection and atherosclerosis: a systematic review. Acta Medica Iranica. 2015:78-88.

64. Birnie DH, Holme ER, McKay IC, Hood S, McColl KE, Hillis WS, et al. Association between antibodies to heat shock protein 65 and coronary atherosclerosis. Possible mechanism of action of Helicobacter pylori and other bacterial infections in increasing cardiovascular risk. European heart journal. 1998;19(3):387-94.

65. Kanbay M, Gür G, Arslan H, Yilmaz U, Boyacioĝlu S. Does eradication of Helicobacter pylori infection help normalize serum lipid and CRP levels? Digestive diseases sciences. 2005;50(7):1228-31.

66. Blum A, Tamir S, Mualem K, Ben-Shushan RS, Keinan-Boker L, Paritsky M, et al. Endothelial dysfunction is reversible in Helicobacter pylori-positive subjects. Am J Med. 2011;124(12):1171-4.

67. Coskun S, Kasirga E, Yilmaz O, Bayindır P, Akil I, Yuksel H, Polat M, Sanlidag T, et al. Is Helicobacter pylori related to endothelial dysfunction during childhood? Pediatr Int. 2008;50(2):150-3.

68. Oshima T, Ozono R, Yano Y, Oishi Y, Teragawa H, Higashi Y, Yoshizumi M, Kambe M, et al. Association of Helicobacter pyloriinfection with systemic inflammation and endothelial dysfunction 
in healthy male subjects. J Am Coll Cardiol. 2005;45(8):1219-22.

69. Sipponen P, Laxen F, Huotari K, Härkönen M. Prevalence of low vitamin B12 and high homocysteine in serum in an elderly male population: association with atrophic gastritis and Helicobacter pylori infection. Scand J Gastroenterol. 2003;38(12):1209-16.

70. Tamura A, Fujioka T, Nasu M. Relation of Helicobacter pylori infection to plasma vitamin B12, folic acid, and homocysteine levels in patients who underwent diagnostic coronary arteriography. Am J Gastroenterol. 2002;97(4):861-6.

71. Santarelli L, Gabrielli M, Cremonini F, Santoliquido A, Candelli M, Nista EC, Pola P, Gasbarrini G, Gasbarrini A, et al. Atrophic gastritis as a cause of hyperhomocysteinaemia. Aliment Pharmacol Ther. 2004;19(1):107-11.

72. Kutluana U, Simsek I, Akarsu M, Kupelioglu A, Karasu S, Altekin E, et al. Is there a possible relation between atrophic gastritis and premature atherosclerosis? Helicobacter. 2005;10(6):623-9.

73. Murray LJ, Bamford KB, O'Reilly DP, McCrum EE, Evans AE. Helicobacter pylori infection: relation with cardiovascular risk factors, ischaemic heart disease, and social class. Heart. 1995;74(5):497-501.

74. Hoffmeister A, Rothenbacher D, Bode G, Persson K, März W, Nauck MA, Brenner H, Hombach V, Koenig W, et al. Current infection with Helicobacter pylori, but not seropositivity to Chlamydia pneumoniae or cytomegalovirus, is associated with an atherogenic, modified lipid profile. Arterioscler Thromb Vasc Biol. 2001;21(3):427-32.

75. Laurila A, Bloigu A, Näyhä S, Hassi J, Leinonen M, Saikku P, et al. Association of Helicobacter pylori infection with elevated serum lipids. Atherosclerosis. 1999;142(1):207-10.

76. Rocha VZ, Libby P. Obesity, inflammation, and atherosclerosis. Nature Reviews Cardiology. 2009;6(6):399.

77. Gillum RF. Infection with Helicobacter pylori, coronary heart disease, cardiovascular risk factors, and systemic inflammation: the Third National Health and Nutrition Examination Survey. J Natl Med Assoc. 2004;96(11):1470.

78. de Luis DA, Lahera M, Cantón R, Boixeda D, San Román AL, Aller R, de La Calle H, et al. Association of Helicobacter pylori infection with cardiovascular and cerebrovascular disease in diabetic patients. Diabetes Care. 1998;21(7):1129-32.

79. Polyzos SA, Kountouras J, Zavos C, Deretzi G. The association between Helicobacter pylori infection and insulin resistance: a systematic review. Helicobacter. 2011;16(2):79-88.

80. Ando T, Ishikawa T, Takagi T, Imamoto E, Kishimoto E, Okajima A, Uchiyama K, Handa O, Yagi N, Kokura S, Naito Y, et al. Impact of $\mathrm{H}$ elicobacter pylori Eradication on Circulating Adiponectin in Humans. Helicobacter. 2013;18(2):158-64.

81. Migneco A, Ojetti V, Specchia L, Franceschi F, Candelli M, Mettimano M, Montebelli R, Savi L, Gasbarrini G, et al. Eradication of Helicobacter pylori infection improves blood pressure values in patients affected by hypertension. Helicobacter. 2003;8(6):585-9.

82. Adachi K, Arima N, Takashima T, Miyaoka Y, Yuki M, Ono M, Komazawa Y, Kawamura A, Fujishiro H, Ishihara S, Kinoshita Y, et al. Pulse-wave velocity and cardiovascular risk factors in subjects with 
Helicobacter pylori infection. Journal of gastroenterology hepatology. 2003;18(7):771-7.

83. Gabrielli M, Santoliquido A, Cremonini F, Cicconi V, Candelli M, Serricchio M, Tondi P, Pola R, Gasbarrini G, Pola P, Gasbarrini A, et al. CagA-positive cytotoxic H. pylori strains as a link between plaque instability and atherosclerotic stroke. European heart journal. 2004;25(1):64-8.

84. De Bastiani R, Gabrielli M, Ubaldi E, Benedetto E, Sanna G, Cottone C, Candelli M, Zocco Maria A, Saulnier N, Santoliquido A, Papaleo P, et al. High prevalence of Cag-A positive H. pylori strains in ischemic stroke: a primary care multicenter study. Helicobacter. 2008;13(4):274-7.

85. Kowalski M. Helicobacter pylori (H. pylori) infection in coronary artery disease: influence of $\mathrm{H}$. pylori eradication on coronary artery lumen after percutaneous transluminal coronary angioplasty. The detection of $\mathrm{H}$. pylori specific DNA in human coronary atherosclerotic plaque. Journal of physiology pharmacology: an official journal of the Polish Physiological Society. 2001;52(1 Suppl 1):3-1.

86. Huang B, Chen Y, Xie Q, Lin G, Wu Y, Feng Y, Li J, Zhuo Y, Zhang P, et al. CagA-positive Helicobacter pylori strains enhanced coronary atherosclerosis by increasing serum OxLDL and HsCRP in patients with coronary heart disease. Digestive diseases sciences. 2011;56(1):109-14.

87. Whincup P, Danesh J, Walker M, Lennon L, Thomson A, Appleby P, Hawkey C, Atherton J, et al. Prospective study of potentially virulent strains of Helicobacter pylori and coronary heart disease in middle-aged men. Circulation. 2000;101(14):1647-52.

88. He C, Yang Z, Lu NH. Helicobacter pylori an infectious risk factor for atherosclerosis?. Journal of atherosclerosis and thrombosis. 2014:25775.

89. Vijayvergiya R, Vadivelu R. Role of Helicobacter pylori infection in pathogenesis of atherosclerosis. World J Cardiol. 2015;7(3):134.

90. Longo-Mbenza B, Nsenga JN, Mokondjimobe E, Gombet T, Assori IN, Ibara JR, Ellenga-Mbolla B, Vangu DN, Fuele SM, et al. Helicobacter pylori infection is identified as a cardiovascular risk factor in Central Africans. Vasc Health Risk Manag. 2012;8:455.

91. Park MJ, Choi SH, Kim D, Kang SJ, Chung SJ, Choi SY, Yoon DH, Lim SH, Kim YS, Yim JY, Kim JS, et al. Association between Helicobacter pylori seropositivity and the coronary artery calcium score in a screening population. Gut Liver. 2011;5(3):321.

92. Jha HC, Prasad J, Mittal A. High immunoglobulin A seropositivity for combined Chlamydia pneumoniae, Helicobacter pylori infection, and high-sensitivity C-reactive protein in coronary artery disease patients in India can serve as atherosclerotic marker. Heart vessels. 2008;23(6):390.

93. Tamer GS, Tengiz I, Ercan E, Duman C, Alioglu E, Turk UO, et al. Helicobacter pylori seropositivity in patients with acute coronary syndromes. Digestive diseases sciences. 2009;54(6):1253.

94. Nikolopoulou A, Tousoulis D, Antoniades C, Petroheilou K, Vasiliadou C, Papageorgiou N, Koniari K, Stefanadi E, Latsios G, Siasos G, Stefanadis C, et al. Common community infections and the risk for coronary artery disease and acute myocardial infarction: evidence for chronic over-expression of tumor necrosis factor alpha and vascular cells adhesion molecule-1. Int J Cardiol. 2008;130(2):24650 . 
95. Arias E, Martinetto H, Schultz M, Ameriso S, Rivera S, Lossetti O, Sevlever G, et al. Seminested polymerase chain reaction (PCR) for detecting Helicobacter pylori DNA in carotid atheromas. Diagn Mol Pathol. 2006;15(3):174-9.

96. Kilic A, Onguru O, Tugcu H, Kilic S, Guney C, Bilge Y, et al. Detection of cytomegalovirus and Helicobacter pylori DNA in arterial walls with grade III atherosclerosis by PCR. Polish journal of microbiology. 2006;55(4):333-7.

97. Ciervo A, Mancini F, Sale P, Russo A, Cassone A. Real-time polymerase chain reaction and laser capture microdissection: an efficient combination tool for Chlamydophila pneumoniae DNA quantification and localization of infection in atherosclerotic lesions. Int $\mathrm{J}$ ImmunoPathol Pharmacol. 2008;21(2):421-8.

98. Sulewska A, Modrzejewski W, Kovalchuk O, Kasacka I, Jackowski R, Hirnle T, Musiał W, Chyczewski L, et al. Attempts to detect Helicobacter pylori in atherosclerotic plaques. Roczniki Akademii Medycznej w Bialymstoku. 2004;49:239-41.

99. Rahmani Y, Mohammadi S, Rai A, Zalei B, Shahmohammadi A. Association of Helicobacter Pylori with Presence of Myocardial Infarction in Iran: A Systematic Review and Meta-Analysis. Ethiopian journal of health sciences. 2017;27(4):433-40.

100. Danesh J, Peto R. Risk factors for coronary heart disease and infection with Helicobacter pylori: meta-analysis of 18 studies. Bmj. 1998;316(7138):1130-2.

101. Yu XJ, Yang X, Feng L, Wang LL, Dong QJ. Association between Helicobacter pylori infection and angiographically demonstrated coronary artery disease: A meta-analysis. Experimental therapeutic medicine. 2017;13(2):787-93.

102. Yu M, Zhang Y, Yang Z, Ding J, Xie C, Lu N, et al. Association between Helicobacter pylori infection and stroke: a meta-analysis of prospective observational studies. Journal of Stroke Cerebrovascular Diseases. 2014;23(9):2233-9.

103. Mayr M, KiechI S, Mendall MA, Willeit J, Wick G, Xu Q, et al. Increased risk of atherosclerosis is confined to CagA-positive Helicobacter pylori strains: prospective results from the Bruneck study. Stroke. 2003;34(3):610-5.

104. Cremonini F, Gabrielli M, Gasbarrini G, Pola P, Gasbarrini A. The relationship between chronic H. pylori infection, CagA seropositivity and stroke: meta-analysis. Atherosclerosis. 2004;173(2):253-9.

105. Sun J, Rangan P, Bhat SS, Liu L. A Meta-Analysis of the Association between H elicobacter pylori Infection and Risk of Coronary Heart Disease from Published Prospective Studies. Helicobacter. 2016;21(1):11-23.

\section{Figures}


Odds Lower Upper

ratio limit limit Z-Value $p$-Value

$\begin{array}{lrlrrr}\text { Ashtari } & 4.077 & 1.840 & 9.033 & 3.462 & 0.001 \\ \text { Abibiglou } & 3.109 & 0.121 & 79.641 & 0.686 & 0.493 \\ \text { Izadi } & 76.034 & 4.272 & 1353.302 & 2.948 & 0.003 \\ \text { Gharehdaghi } & 21.098 & 1.209 & 368.230 & 2.090 & 0.037 \\ \text { Sadeghian } & 0.333 & 0.013 & 8.509 & -0.665 & 0.506 \\ \text { Nozari } & 2.154 & 0.977 & 4.747 & 1.903 & 0.057 \\ \text { Yazdi } & 3.034 & 0.122 & 75.463 & 0.677 & 0.499 \\ \text { Pouria } & 23.044 & 1.263 & 420.370 & 2.118 & 0.034 \\ \text { Sayyah } & 4.889 & 1.809 & 13.211 & 3.129 & 0.002 \\ \text { Ansari } & 2.273 & 1.259 & 4.105 & 2.723 & 0.006 \\ \text { Davoudi } & 1.034 & 0.543 & 1.971 & 0.103 & 0.918 \\ \text { Vafaeimanesh } & 76.760 & 4.617 & 1276.162 & 3.027 & 0.002 \\ & 2.508 & 1.835 & 3.428 & 5.767 & 0.000\end{array}$

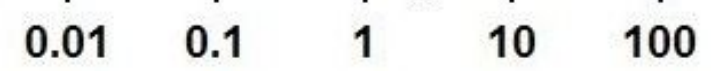

Figure 1

Flowchart of included articles according to PRISMA strategy.

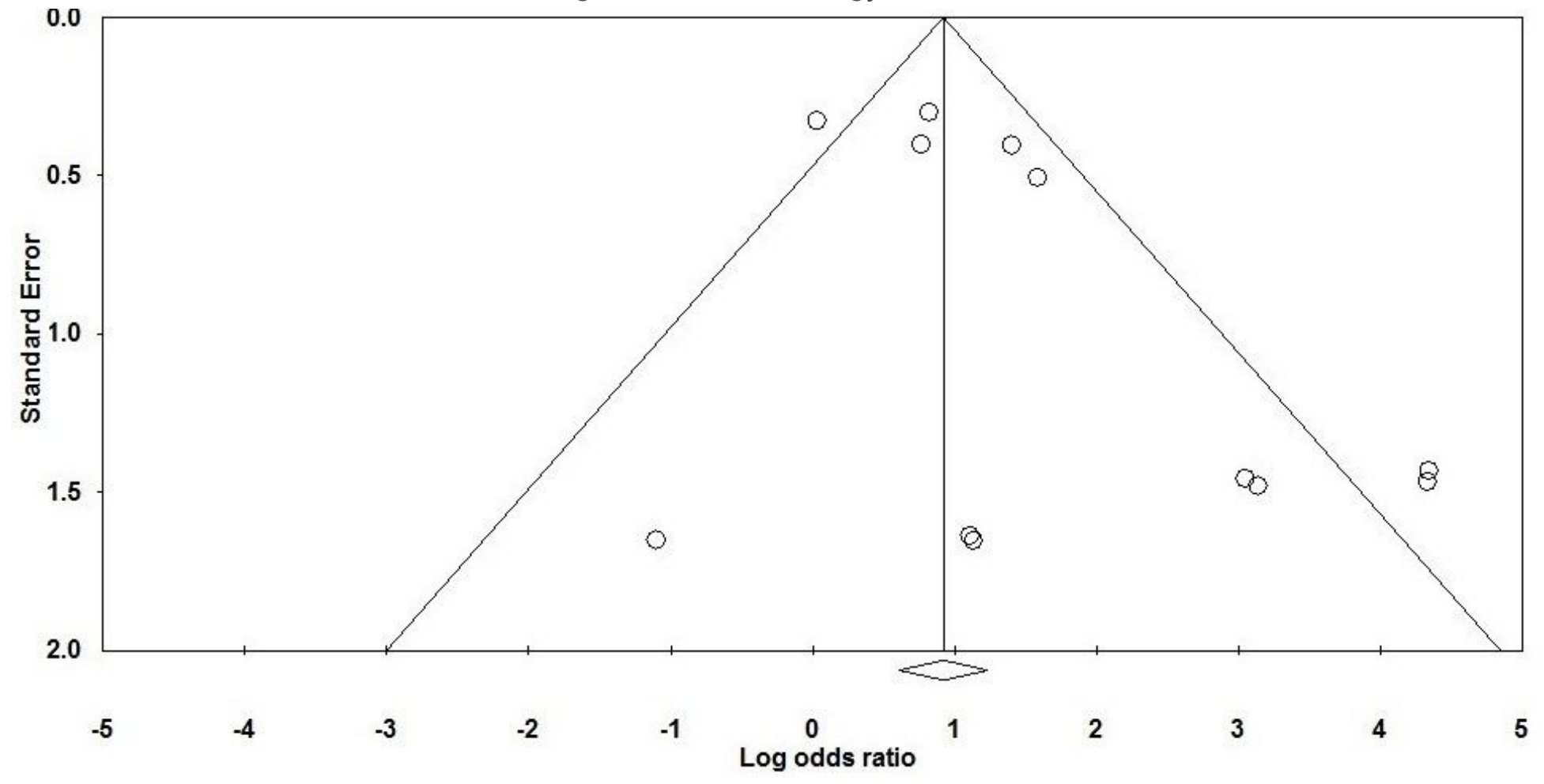

Figure 2

Forrest plot of the probable link between $\mathrm{H}$. pylori infection and atherosclerosis in Iranian CAD patients. 

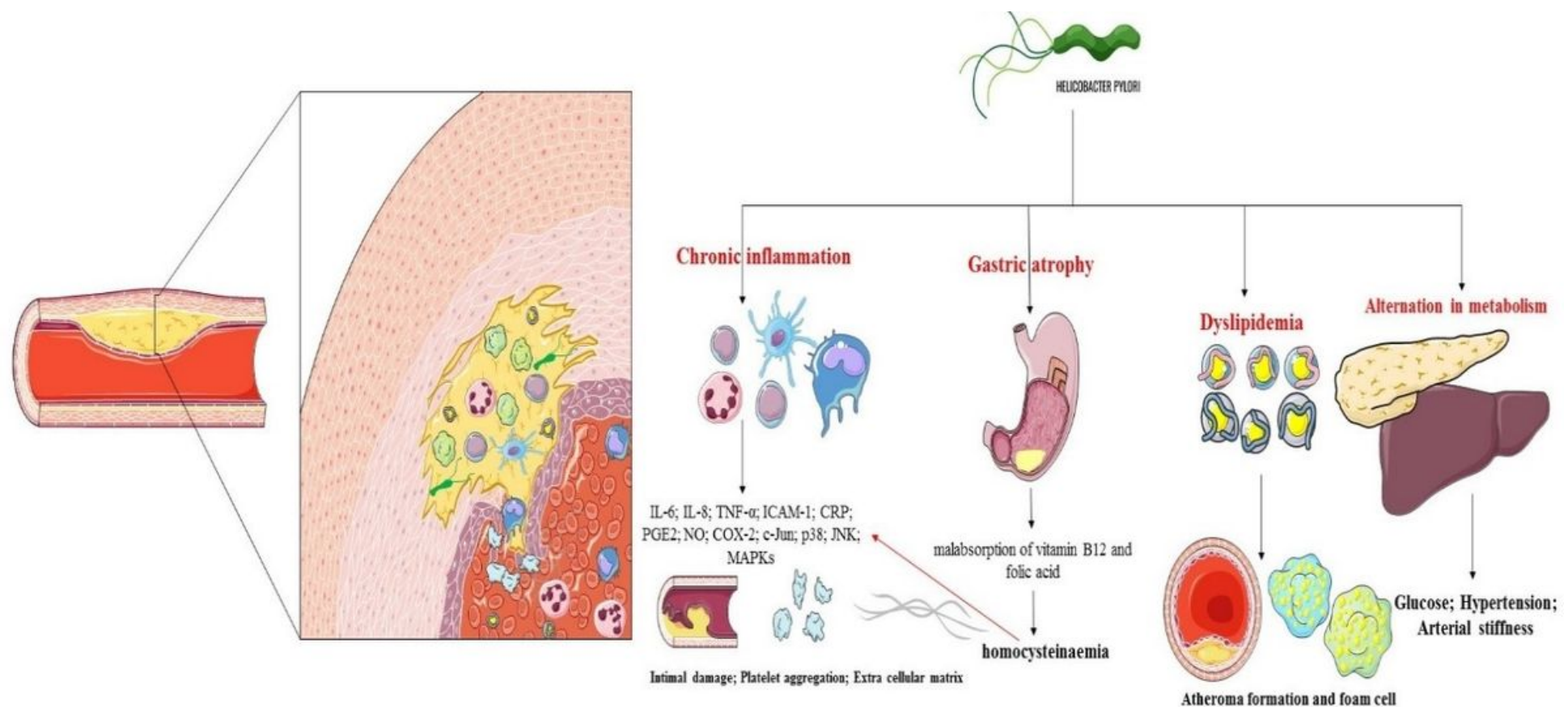

Figure 3

Funnel plot of standard error by Log odds ratio (OR).
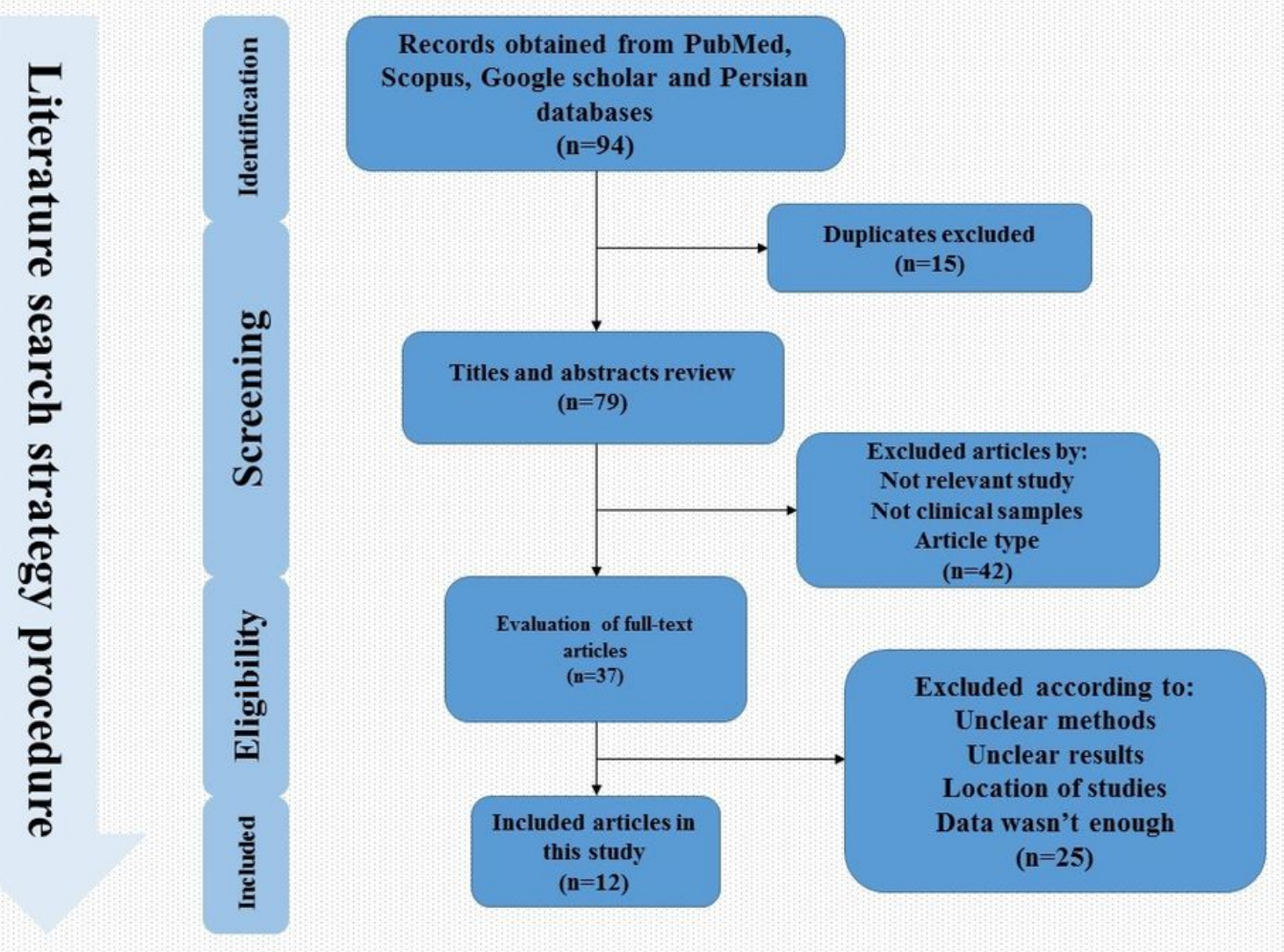

Figure 4

Hypothetic scheme of H. pylori infection and atherosclerosis. 